\section{Endoscopic injections of Teflon to treat urinary incontinence in women}

Various forms of treatment have been developed to cure urinary stress incontinence in women. All surgical procedures aim to increase the urethral resistance to urine outflow and eventually to restore a normal angle between the proximal urethra and the bladder neck. ${ }^{1}$ Politano proposed using perineal injections of Teflon to treat incontinence in men after transurethral resection of the prostate and extended the technique to women. ${ }^{2}{ }^{3}$ Heer injected Teflon into the wall of the urethra to increase its length and closing pressure.$^{4}$ For the past three years we have used an endoscopic technique for giving injections of Teflon to women suffering from incontinence.

\section{Patients, methods, and results}

We treated 56 women aged 30-86 (mean 59) suffering from urinary stress incontinence. Twelve patients presented with cystoceles, four of whom had had an operation for this; 19 had undergone hysterectomy; four had undergone perineal amputation; and eight had had several operations to treat incontinence by classic vesicosuspension using sling procedures. Follow up ranged from three to 25 (mean 12) months.

An 8 French gauge polyethylene catheter ending in a needle was guided through the shaft of a regular cystoscope. The needle was inserted deep into the urethral wall, about $1 \mathrm{~cm}$ below the bladder neck. Teflon was injected using a small syringe with a metallic sheet and piston (Storz). About $3 \mathrm{ml}$ was injected at 1500,1800 , and 2100 (total around $10 \mathrm{ml}$ ). A bladder catheter was used for 24 hours afterwards, and patients stayed in hospital for about three days. Oral broad spectrum antibiotics were always prescribed for two weeks. Most injections were performed under general anaesthesia, but some were done under local anaesthesia or even sedation. When only partial improvement occurs Teflon injections can be repeated without difficulty after six to eight weeks, when the inflammation has resolved.

The table shows that $39(70 \%)$ of the 56 patients were completely cured, 29 after one, eight after two, and two after three injections. Cure was defined

Results of endoscopic Teflon injection for urinary incontinence in 56 women

\begin{tabular}{cccc}
\hline & \multicolumn{3}{c}{ No of patients showing: } \\
\cline { 2 - 4 } No of injections & Success & Improvement & Failure \\
\hline 1 & 29 & 5 & 2 \\
2 & 8 & 3 & 4 \\
3 & 2 & 1 & 1 \\
\hline 4 & $39(70 \%)$ & $9(16 \%)$ & $8(14 \%)$ \\
\hline
\end{tabular}

as the absence of leaking during the filling phase of a cystometrogram and was confirmed by questioning and examining the patient. Nine patients $(16 \%)$ showed substantial improvement in continence but complained of some urgency. Treatment failed in eight patients $(14 \%)$, of whom two had undergone perineal amputation followed by radiotherapy, one had interstitial cystitis, and one had neurological disorders. Complications were minimal. A few patients needed bladder catheters for two or three days. One woman with persistent urinary retention was treated by internal urethrotomy. Urethral burning and discomfort were experienced by most patients for one week.

\section{Comment}

Teflon paste is a suspension of fine polymer particles in glycerine and polysorbate. It has been used for years in surgery and otolaryngology and is an inert material that produces minimal inflammation. ${ }^{5}$ We initially used this technique only in patients who had had several previous operations without success. As the results were encouraging we used it for all patients eligible for classic operations. We noted minor complications such as occasional retention and bladder discomfort. Although no abscess developed, we prescribed broad spectrum antibiotics for two weeks.

Our main fear was of inducing obstruction of the bladder outlet, but measurement of urine flow after injection of Teflon showed an average decrease in rate of only $5 \mathrm{ml} / \mathrm{s}$, whereas a urethral pressure profile showed an appreciable increase in the functional length of the urethra. This technique has obvious advantages: hospital stay is shortened, obesity or previous surgical procedures do not prevent injection, and it does not hinder later open surgery.
'Stanton SL, Tanagho EA, eds. Surgery of female incontinence. Berlin, Heidelberg, New York: Springer-Verlag, 1980.

2 Politano VA, Small MP, Harper JM, Lynne CM. Periurethral Teflon injection for urinary incontinence. 7 Urol 1974;111:180-3.

${ }^{3}$ Politano VA. Periurethral polytetrafluorethylene injection for urinary incontinence. $\mathcal{F}$ Urol 1982;127:439-42.

${ }^{4}$ Heer H. Die Behandlung der Härinkontinenz mit der Teflonpaste. Urol Int $1977 ; 32: 295-302$.

5 Goff GE. Teflon injection for vocal cord paralysis. Arch Otolaryngol 1969; 90:98-102.

(Accepted 28 September 1983)

Department of Urology, University Clinics of Brussels, Erasme Hospital, Brussels, Belgium

C C SCHULMAN, MD, professor and chief of urology

J SIMON, MD, consultant urologist

E WESPES, MD, registrar

F GERMEAU, MD, consultant urologist

Correspondence to: Professor C C Schulman, Department of Urology, University Clinics of Brussels, Erasme Hospital, 808 Route de Lennik, 1070 Brussels, Belgium.

\section{Penicillamine induced myasthenia reactivated by gold}

We describe a patient whose penicillamine induced myasthenia was reactivated by gold. Her poor sulphoxidation state may have been related to the original induction of myasthenia.

\section{Case report}

A 52 year old woman developed seronegative rheumatoid arthritis in 1970 , for which she was treated with indomethacin and aspirin until it deteriorated in 1976. Prednisolone $5 \mathrm{mg}$ daily was started but phased out after 18 months. In January 1977 she began penicillamine $125 \mathrm{mg}$ daily, gradually increasing to $500 \mathrm{mg}$ daily by August 1980 .

In June 1981 she began to feel increasingly tired. In November she had intermittent left ptosis and diplopia, variable weakness of neck flexors and triceps, with no bulbar or other weakness. Reflexes and sensation were intact. Edrophonium testing and tests for antiacetylcholine receptor and antinuclear antibodies gave positive results. Electromyography, plain chest radiography, and immunoglobulins IgA and IgG showed nothing abnormal. IgM concentration was $0.4 \mathrm{~g} / 1$ (normal 0.6-3.0). Her HLA state was A1, A2, B12, DR2, DR4. Penicillamine induced myasthenia gravis was diagnosed and penicillamine stopped. After two months she had only occasional ptosis and after five months (May 1982) no myasthenic symptoms.

Her arthritis deteriorated, so fenclofenac $600 \mathrm{mg}$ twice daily was prescribed in March 1982. After two weeks a rash developed which resolved on withdrawing fenclofenac, recurring when she was rechallenged. Her myasthenia did not recur. In July 1982 she began sodium aurothiomalate $10 \mathrm{mg}$ weekly, increasing by $10 \mathrm{mg}$ a week for five weeks, when she developed a rash. Simultaneously her ptosis and diplopia reappeared. She required prednisolone (initially $10 \mathrm{mg}$ daily) for the rash, the dosage reducing over five months, and pyridostigmine (initially $60 \mathrm{mg}$ four times a day) for four months. Her myasthenia had resolved after six months.

\section{Comment}

No previous reports have described recurrence of penicillamine induced myasthenia when gold has been subsequently given. Our patient's myasthenia had virtually disappeared when she suffered a toxic reaction to fenclofenac, but this did not provoke recurrence of her myasthenia. Thus it is unlikely that the return of symptoms with gold was due to a non-specific upset. Since gold alone has never been reported to cause myasthenia, it probably aggravated a penicillamine induced defect.

The mechanism of action of penicillamine is not clear, but it affects the immune system and has induced several autoimmune disorders. It may directly stimulate oligoclonal B cell activity, upset the balance between $T$ helper and suppressor cells, or alter antigens by hapten formation. The sulphydryl group of penicillamine reduces disulphide bonds in several proteins. Acetylcholine receptor subunits also contain vulnerable disulphide bonds. Penicillamine binds, ${ }^{1}$ probably via these sulphydryl links, to subunits of electric fish acetylcholine receptor, reducing their affinity for acetylcholine. This may directly affect neuromuscular transmission, as in guinea pigs, where penicillamine 
reduces the amplitude of miniature end plate potentials. One possibly analogous case in man has been described, in which a patient noted weakness within 24 hours of beginning penicillamine, improving immediately when the drug was stopped. ${ }^{2}$ Equally this binding suggests a mechanism for antigenic alteration of acetylcholine receptor and loss of tolerance.

Carbocysteine is structurally similar to penicillamine, and people with a low capacity for producing sulphoxides of carbocysteine may be similarly unable to metabolise penicillamine. Poor sulphoxidisers of carbocysteine are more likely to develop proteinuria or thrombocytopenia when taking penicillamine. ${ }^{3}$ Our patient was a very poor sulphoxidiser (index 52). Possibly this inability to metabolise the sulphydryl group makes interaction with acetylcholine receptor more likely.

Penicillamine toxicity, especially proteinuria or marrow suppression, may be more likely in patients who have had a toxic reaction to gold. The order of treatment with gold and penicillamine probably makes no difference to recurrence of toxicity. ${ }^{5}$

Caution should be exercised in prescribing gold to a patient who has developed penicillamine induced myasthenia.

${ }^{1}$ Bever CT, Hai Wang Chang, Penn AS, Jaffe IA, Bock E. Penicillamine induced myasthenia gravis: effects of penicillamine on acetylcholine receptor. Neurology $1982 ; 32: 1077-82$.

2 Atcheson SG, Ward JR. Ptosis and weakness after start of D-penicillamine therapy. Ann Intern Med 1978;89:939-40.

3 Panayi GS, Huson G, Shah RR, et al. Deficient sulphoxidation status and D-penicillamine toxicity. Lancet $1983 ; \mathrm{i}: 414$

${ }^{4}$ Smith PJ, Swinburn WR, Swinson DR, Stewart IM. Influence of previous gold toxicity on subsequent development of penicillamine toxicity. Br Med f 1982;285:595-6.

s Steves MM, Hunter JA, Murdoch RM, Capell HA. Does the order of second-line treatment in rheumatoid arthritis matter? $\mathrm{Br}$ Med $\mathcal{F}$ $1982 ; 284: 79-81$

(Accepted 23 September 1983)

Department of Neurology, Queen Elizabeth Hospital, Birmingham B15 2TH

A P MOORE, MB, MRCP, registrar

A C WILLIAMS, MD, MRCP, consultant neurologist

Good Hope Hospital, Sutton Coldfield, West Midlands

P HILLENBRAND, MB, FRCP, consultant physician

Correspondence to: Dr A P Moore, Glasgow University Department of Neurology, Institute of Neurological Sciences, Southern General Hospital, Glasgow G51 4TF.

\section{Normal energy intake in undernourished patients with Crohn's disease}

Malnutrition is common in Crohn's disease and an important cause is widely believed to be reduced food intake as a consequence of anorexia or fear of abdominal pain. Scientific data, however, are remarkably few. We have investigated the energy intakes of a group of chronically malnourished outpatients with Crohn's disease and compared the results with those in a group of well nourished outpatients with ulcerative colitis and a group of healthy subjects.

\section{Patients, methods, and results}

We studied 26 patients (17 men) with Crohn's disease and 22 (12 men) with ulcerative colitis. All were ambulant and attending a gastrointestinal clinic, and their mean ages (1 SD) were 36 (14) and 43 (14) years, respectively. Mean duration of disease was 10 years in the patients with Crohn's disease and eight years in those with ulcerative colitis. We also studied 22 healthy subjects (13 men), whose mean age (1 SD) was 34 (15) years.

Patients with inflammatory bowel disease had their height and weight measured, their weight being expressed as a percentage of ideal. ${ }^{1} \mathrm{~A}$ semiweighed dietary assessment was carried out in all subjects. ${ }^{2}$ Subjects were provided with a pair of Salter Slimmer's Scales and asked to complete a three day dietary diary on two weekdays and one weekend day, recording everything they ate and drank, using either weight, volume, or handy measures. Mean daily energy intake was calculated using a computer tape of McCance and Widdowson's The Composition of Foods ${ }^{3}$ and from manufacturers' information. Statistical analysis was by unpaired Student's $t$ test.

Mean weight (1 SD) was $86.8(6.4) \%$ of ideal in patients with Crohn's disease and $113.8(19.9) \%$ of ideal in those with ulcerative colitis. The figure shows the mean daily energy intakes of the three groups; there were no significant differences.

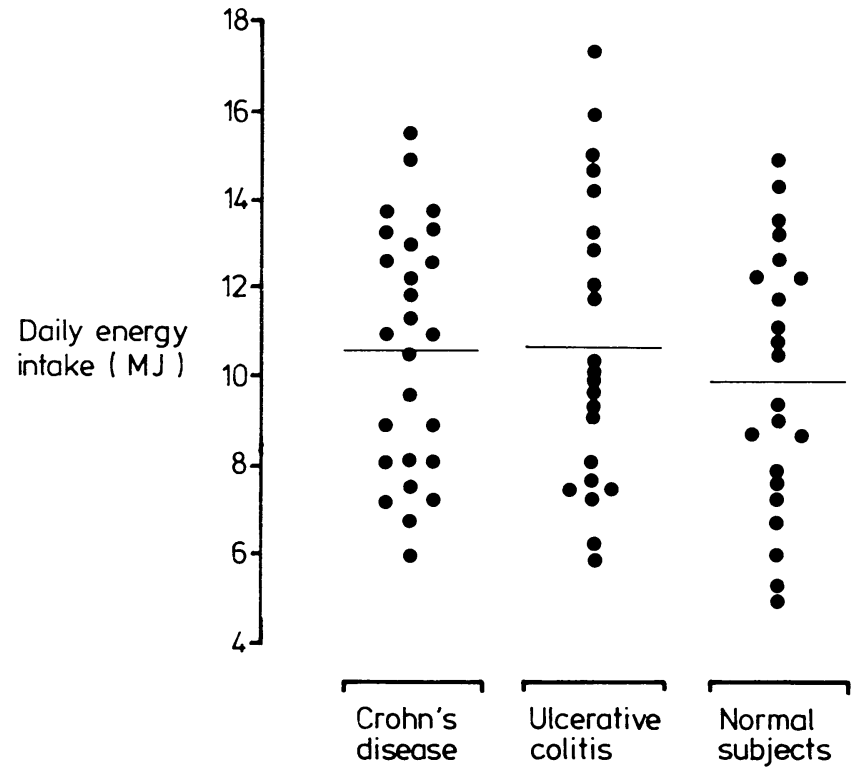

Daily energy intakes in patients with Crohn's disease, patients with ulcerative colitis, and normal subjects. Bars represent group means.

Conversion: SI to traditional units-Energy: $4 \cdot 18 \mathrm{MJ} \approx 1000 \mathrm{kcal}$.

\section{Comment}

These results show that malnourished outpatients with Crohn's disease have similar energy intakes to those of well nourished outpatients with ulcerative colitis and healthy subjects. Undernutrition might therefore be accounted for by malabsorption, inflammation, and enteric loss of nutrients, and possibly the increased metabolic demands of the disease cannot be compensated for by an apparently normal energy intake. In undernourished ambulatory patients with Crohn's disease increasing the energy intake by enteral supplementation may result in an increase in weight and other nutritional variables. ${ }^{4}$ Similarly parenteral hyperalimentation in acute severe Crohn's disease may improve nutrition and contribute to primary management. ${ }^{5}$ These observations support the concept that undernourished patients with Crohn's disease may have a "relative energy deficiency."

Our study suggests that a reduced food intake is not a common feature in chronically undernourished patients with Crohn's disease; nevertheless, this does not in any way obviate the important role of nutritional care in their management.

1 Society of Actuaries. Build and blood pressure studies. Vols 1 and 2. Chicago, 1959.

2 Nelson M, Nettleton P. Dietary survey methods. I: A semi weighed technique for measuring dietary intake within families. F Hum Nutr 1980;34: 325-8.

3 Paul AA, Southgate DAT. McCance and Widdowson's the composition of foods. HMSO, 1978.

${ }^{4}$ Harries AD, Jones LA, Danis V, et al. Supplemented oral nutrition in Crohn's disease. A controlled trial. Lancet $1983 ; \mathrm{i}: 887-90$.

5 Reilly J, Ryan JA, Strole W, Fischer JE. Hyperalimentation in inflammatory bowel disease. Am $\mathcal{F}$ Surg 1976;131:192-200.

(Accepted 30 November 1983)

Departments of Dietetics and Gastroenterology, University Hospital of Wales, Heath Park, Cardiff CF4 4XW

L A JONES, SRD, senior dietitian

A D HARRIES, MA, MRCP, senior lecturer in medicine

J RHODES, MD, FRCP, consultant gastroenterologist

Department of Medicine, St James's University Hospital, Leeds

R V HEATLEY, MD, MRCP, senior lecturer in medicine

Correspondence to: Mrs L A Jones. 